\title{
Primate Social Cognition and the Core Human Knowledge Concept*
}

\author{
John Turri \\ john.turri@gmail.com
}

Abstract: I review recent work from armchair and cross-cultural epistemology on whether humans possess a knowledge concept as part of a universal "folk epistemology." The work from armchair epistemology fails because it mischaracterizes ordinary knowledge judgments. The work from cross-cultural epistemology provides some defeasible evidence for a universal folk epistemology. I argue that recent findings from comparative psychology establish that humans possess a species-typical knowledge concept. More specifically, recent work shows that knowledge attributions are a central part of primate social cognition, used to predict others' behavior and guide decision-making. The core primate knowledge concept is that of truth detection (across different sensory modalities) and retention (through memory) and may also include rudimentary forms of indirect truth discovery through inference. In virtue of their evolutionary heritage, humans inherited the primate social-cognitive system and thus share this core knowledge concept.

Keywords: primates; social cognition; knowledge attributions; folk epistemology

Word count: 3336

* This is the penultimate version (20 September 2015) of a paper to appear in M. Mizumoto, S. Stich, and E. McCready (Eds.), Epistemology for the Rest of the World: Linguistic and Cultural Diversity and Epistemology (Oxford University Press). Please cite the final, published version if possible. 
Some important philosophical research focuses on concepts and phenomena unfamiliar from everyday life. To take just a few examples, some philosophers study the properties of formal languages, the metaphysical implications of quantum mechanics, or the ultimate basis of attribute agreement. It is fair game for philosophers to investigate concepts and theories from nearly any specialized field of inquiry, including the natural and symbolic sciences. Because these specialized fields of inquiry investigate phenomena unfamiliar from everyday life, they inevitably introduce new concepts and categories, and they often produce surprising or counterintuitive results, such as the relativity of simultaneity or quantum entanglement. These fields are not beholden to commonsense: that the results might be shocking is not a serious objection, even if it motivates people to seek objections.

By contrast, much philosophical research aims to illuminate concepts important to us in our everyday lives. With respect to these concepts, philosophers have long assumed that patterns in ordinary usage and commonsense should constrain philosophical theorizing. The basic assumption behind this approach is these patterns can be used as evidence to define or otherwise characterize the relevant concepts, to illuminate the fundamental principles determining membership in the concept's extension. "Ordinary-language philosophy" was an iconic twentieth-century expression of this sentiment, epitomized in the work or J.L. Austin, who wrote that "ordinary language" should get "the first word" in philosophical theorizing (Austin 1956, p. 11). But the sentiment is of much older vintage. For example, John Locke claimed that a theory of knowledge should be informed by how we ordinarily act and talk about knowledge (Locke 1690/1975, book 4.11.3-8). And Aristotle wrote that a philosophical theory of the good life should be evaluated "in 
the light not only of our conclusion and our premises, but also of what is commonly said about it” (Aristotle 350 BCE/1941, 1098b, 9-11).

To characterize ordinary thought and talk, many contemporary philosophers often draw on their own experiences, social observation, and reflections about what we would say about certain situations (Ducasse 1941, ch. 10; Fodor 1964; Austin 1966; Craig 1990; Jackson 1998, ch. 2). However, this approach is subject to at least two concerns. First, it frequently mischaracterizes ordinary thought and talk (Naess 1938; Colaço, Buckwalter, Stich \& Machery 2014; Turri 2016a). Second, it is almost always limited to the culture and native language of the philosopher in question, who frequently is also a highly privileged, highly educated male (Stich 2001; Weinberg, Nichols \& Stich 2001; Buckwalter \& Stich 2014). The solution to the first concern is straightforward: use more reliable empirical tools from cognitive and social science (Nichols 2004; Murphy 2015; Buckwalter \& Turri 2016). In recent years, this solution has been applied, with increasing effectiveness, under the label of "experimental philosophy" (for reviews, see Knobe, Buckwalter, Nichols, Robbins, Sarkissian \& Sommers 2012; Alexander 2012; Sytsma \& Livengood 2015). The solution to the second concern is also straightforward: study people's judgments across different cultures or languages (e.g. Machery, Mallon, Nichols \& Stich 2004; Knobe \& Burra 2006).

A recent study on knowledge judgments is an excellent example of philosophical research avoiding both concerns at once (Machery, Stich, Rose, Chatterjee, Karasawa, Struchiner, Sirker, Usui \& Hashimoto 2015). The researchers' goal was to test whether people across different cultures distinguished between an agent knowing a proposition and having a justified true belief in 
that proposition. More specifically, the researchers investigated whether, across cultures, people would reliably judge that having a justified true belief did not necessarily suffice to know.

Participants from the United States, Brazil, India, and Japan were tested in their native language. Participants read a story about an agent who gets indirect, testimonial evidence that a certain proposition is true. The proposition turns out to be true, but the agent's evidence is oddly disconnected from what makes the proposition true. For example, in one scenario, Paul's wife, Mary, has been missing for several hours, so he calls the local hospital to ask whether someone by the name of "Mary Jones" was recently admitted. The hospital worker confirms that someone by that name was admitted, so Paul rushes out the door. However, the patient at the local hospital was another woman with the same name as Paul's wife. Nevertheless, Paul's wife was admitted that evening to another hospital several miles away. After reading the story, participants rated whether, as Paul rushes out the door, he knows that his wife was hospitalized. Rates of knowledge attribution differed significantly across cultures. For participants from the United States, Brazil, and Japan, the central tendency was to deny knowledge (70\% to $87 \%$ ). For Indian participants, the central tendency was to attribute knowledge (63\%). Researchers attributed the results for Indian participants to a potential ambiguity whereby the Bengali word ("jáná") used to translate "know" could also mean "belief."

Another recent but earlier set of studies tested participants from the United States and India and produced different results (Turri 2013). The central tendency for United States participants was to deny knowledge (89\%). Similarly, the central tendency for Indian participants was to deny knowledge (85\%). (Without excluding anyone based on their answer to comprehension 
checks, $67 \%$ of Indian participants denied knowledge.) The discrepancy between these earlier results from Indian participants and the later results (described above) could be explained by several factors. First, the two lines of research tested participants differently. The earlier set of studies tested all participants in English, whereas the later study (discussed above) tested participants in their native languages, including Bengali for Indian participants. Second, the two lines of research tested different storylines and used different response options. Third, the two lines of research sampled different populations in India. The population sampled in the earlier studies included few if any people reporting Bengali as a native language (44\% reported English, 30\% Tamil, 19\% Hindi, 15\% Malayalam, and 4\% Marathi, with a few of these participants reporting native competence in multiple languages). (See Turri 2013, p. 10, n. 21). So it could be that Bengali speakers specifically have different intuitions than other people, including people from other ethnic groups in the same region.

Several other recent studies have investigated knowledge judgments about similar scenarios — that is, scenarios where an agent gets evidence for a true proposition, but the evidence is oddly disconnected from what makes the proposition true (Nagel, San Juan \& Mar 2013; Sayedsayamdost 2015; Kim \& Yuan 2015). Researchers looked for intra-societal cultural variation in knowledge judgments. More specifically, they tested people in Western societies (United States, Canada, Britain) with different cultural backgrounds. None of these studies found evidence of intra-societal cultural variation in knowledge judgments.

Overall, then, the balance of evidence currently suggests that people across a variety of cultures and languages reliably deny that knowledge is present in such cases. This has led some 
researchers to hypothesize that these judgments might reflect "an underlying innate and universal core folk epistemology" (Machery et al. 2015, p. 8). (The researchers caution that further work is required before accepting this hypothesis, including studies testing different scenarios, studies on additional cultures and languages, developmental studies, and studies collecting information on religion, socioeconomic status, age, and education.) The hypothesis predicts that "people in all cultures will possess epistemic concepts requiring more than justification, truth and belief, and in most cultures that concept will be expressed" by the term "commonly translated into English as 'know"' (Machery et al. 2015, p. 8; see also Spicer 2010). This prediction is supported by work in cross-cultural semantics suggesting that all human languages might contain an expression translatable as the English word 'know' (Goddard 2001).

Some theorists have recently argued that we do not need empirical studies of the sort discussed above to conclude that there probably is a knowledge concept universal to all humans (Hannon 2015). The basic idea is that the concept of knowledge arises in all human societies because it "answers to some very general needs of human life and thought" (Craig 1990, p. 2). These needs are "severely practical" and found in even "primitive" human existence (Craig 1990, p. 4). Humans are essentially social beings dependent on information from others to consistently fulfill basic needs. This dependence creates a vulnerability to being harmed by others' incompetence or duplicity. Thus humans have an interest in identifying trustworthy informants. The knowledge concept serves this purpose. More specifically, "The concept of knowledge is used to flag approved sources of information" (Craig 1990, p. 11). An approved informant is someone with a true belief about the topic of interest and who is highly reliable in forming true 
beliefs (Craig 1990, pp. 12, 91; Hannon 2015, p. 773).

If this theory is correct, then the concept of knowledge is the "outcome of certain very general facts about the human situation" (Craig 1990, p. 10), and "we should expect every culture to have a word to express the concept of knowledge" (Hannon 2015, p. 772). But how shall we judge whether it is correct? The theory's proponents defend it based on how well it "matches our everyday practice with the concept of knowledge as actually found" (Craig 1990, p. 3). They claim that it well explains 'the intuitive extension of 'know' ... [and] a variety of facts about the 'phenomenology' of the concept" (Craig 1990, pp. 3-4). In other words, it explains important aspects of the way we ordinarily think and talk about knowledge — features of our "conceptual and linguistic institutions" (Craig 1990, p. 10). To identify these features, the theory's proponents rely on their own experiences, social observation, and reflections about what we would say about certain situations.

Alas, the theory's Achilles heel is predictable. Along with so many others in the recent tradition of "armchair philosophy," the theory's proponents have critically mischaracterized how we ordinarily think and talk about knowledge. Two mischaracterizations stand out.

First, knowledge does not require belief, as those categories are ordinarily understood. Several recent experimental studies have shown that people reliably attribute knowledge at higher rates than they attribute belief (Myers-Schulz \& Schwitzgebel 2013; Murray, Sytsma \& Livengood 2012). In some cases, the majority of people who attribute knowledge also deny belief. Moreover, in many perfectly ordinary contexts, people's knowledge attributions are not based on belief attributions (Turri \& Buckwalter 2017; Turri, Buckwalter \& Rose 2016). The explanation 
for this might be that belief ordinarily understood is connected with feeling in a way that knowledge is not (Buckwalter, Rose \& Turri 2015; Buckwalter \& Turri in press). As William James wrote, "In its inner nature belief . . . is a sort of feeling more allied to the emotions than to anything else" (James 1889: 21; see also Hume 1748/1993 on belief as a feeling).

Second, knowledge does not require reliability, nor do we ordinarily assume that it does. Many contemporary philosophers have simply assumed without argument that knowledge requires reliability. But there is good evidence that unreliably produced knowledge is not only possible but actual (Turri 2012; Turri 2015a). More importantly for present purposes, commonsense epistemology fully embraces the possibility of unreliably produced knowledge. In one recent series of studies (Turri 2016b), up to 90\% of participants attributed knowledge in cases of unreliably produced true belief, while participants overwhelmingly denied knowledge in closely matched controls. Participants consistently attributed knowledge to reliable and unreliable believers at similar rates. Participants attributed knowledge to agents whom they actively classified as unreliable. More generally, participants understood and processed explicit information about (un)reliability, but they did not seem to consult this information when making knowledge judgments.

In light of these findings, I reject the armchair hypothesis about a universal human knowledge concept. It is based on critical mischaracterizations of ordinary thought and talk, resulting in its "explaining" non-existent patterns in commonsense epistemology. To be sure, the armchair hypothesis describes a possible concept that could serve needs that humans actually have. But that possible concept is not the knowledge concept we actually have. (More precisely and humbly, it is not the concept expressed by 'know' in contemporary anglophone societies.) 
Of course, even if that one particular armchair hypothesis is false, it does not follow that there is not a core universal human knowledge concept. The cross-cultural findings on knowledge judgments discussed above provide some evidence for some universal features of human folk epistemology. Another approach to this issue is to blend some motivations from the armchair project and the cross-cultural empirical project. This approach looks for needs that (i) are common to animal life beyond just the human species and (ii) would be well served by cultivating a knowledge concept. Similar to the armchair hypothesis, this approach begins with a thoroughly naturalist assumption that human behavior and institutions are "natural facts to be understood as the outcome of other natural facts" (Craig 1990, p. 9). However, unlike the armchair hypothesis but in keeping with the cross-cultural project, this approach relies on scientific evidence to validate hypotheses.

To illustrate the approach, I will baldly state a hypothesis. Then I will review some evidence supporting it. Then I will discuss some of its implications.

The knowledge concept is not a human creation (contra Craig 1990, p. 3). Instead, the knowledge concept is an integral part of the primate social-cognitive system, which humans inherited. The core of the knowledge concept is truth detection and retention. Its origin is related to the basic need of predicting other organisms' behavior to guide decision-making.

Research on primate social cognition has advanced dramatically over the past fifteen years, beginning with a landmark study introducing a food-competition paradigm to probe for mentalstate representations in chimpanzees (Hare, Call, Agnetta \& Tomasello 2000). This paradigm was vastly more ecologically valid than previous studies, which studied, for instance, how chimpanzees decided to beg humans for food, or whether to use a human's gaze to find hidden food 
items. Using the more ecologically valid approach based on food competition, researchers found that subordinate chimpanzees kept track of which food items dominant chimpanzees currently or recently saw and used this information to decide which food items to retrieve (e.g. Hare, Call \& Tomasello 2001; Kaminski, Call \& Tomasello 2008).

Subsequent variations on the food-competition paradigm showed that chimpanzees actively conceal visual information from others, that they conceal auditory information from others, and that many of the same findings extend to other apes and monkey species (e.g. Flombaum \& Santos 2005; Santos, Nissen \& Ferrugia 2006; Melis, Call \& Tomasello 2006; Marticorena, Ruiz, Mukerji, Goddu \& Santos 2011; for reviews, see Call \& Tomasello 2008; Seed \& Tomasello 2010; Martin \& Santos 2014). (The findings pertain primarily to simian primates (apes and monkeys); findings for other primates are either less consistent (e.g. lemurs) or non-existent (e.g. tarsiers). See Sandel, MacLean \& Call 2011; Bray, Krupenye \& Hare 2014.) Researchers have also found that chimpanzees attribute simple, sensible inferences to others and use this information to guide decision-making (Schmelz, Call \& Tomasello 2011). So, in addition to truth detection and retention, chimpanzees also recognize in others the discovery of truth through inference.

In light of this impressive body of research, the consensus among primatologists is that (simian) non-human primates attribute knowledge to others and thus have a concept of knowledge. This concept pertains to the detection, discovery, and retention of truths and is closely connected to predicting others' behavior and guiding decision-making. Nevertheless, primatologists contend that there is no clear evidence that non-human primates attribute false beliefs to others, from which many conclude that non-human primates lack the concept of belief. Overall, then, the current evidence leads many to conclude that whereas humans use belief-desire psychology, 
non-human primates use a comparatively simpler but still impressive "knowledge-goal" psychology (e.g. Call \& Tomasello 2008).

These findings on primate social cognition have at least two important implications for recent philosophical research on the knowledge concept. First, contrary to the armchair hypothesis discussed earlier, it is a mistake to seek the knowledge concept's origin in distinctively human conditions. Its origin is not human information-sharing practices or other cooperative endeavors. Instead, we inherited the concept from our primate ancestors. This important fact cannot be learned from the armchair but it should inform any serious investigation seeking to understand human social cognition as the "outcome of natural facts" (Craig 1990, p. 9). Moreover, this fact might help explain why some human knowledge attributions are not based on belief attributions. As mentioned above, although non-human primates attribute knowledge, they lack the concept of belief, according to leading primatologists. If that is correct, then non-human primates obviously do not base knowledge attributions on belief attributions. Thus when humans do not base knowledge attributions on belief attributions, it could just be a special instance of a more general fact about primate social cognition.

Second, the primatological findings provide strong evidence for a species-typical knowledge concept in humans. This can be crystalized in a simple argument: primates share a core knowledge concept; humans are primates; therefore, humans share a core knowledge concept. Again, this core concept pertains to detecting, discovering, and retaining truths and is central to predicting behavior (for a defense of a theory of knowledge along these lines, including theoretical and empirical reviews, see Turri 2012; Turri 2015a; Turri 2015b; Turri 2015c; Turri 2015d; Turri 2016c; Turri, Friedman \& Keefner 2017; Turri in press a; Turri in press b). This in turn 
helps to settle one question motivating recent cross-cultural epistemological research, namely, whether there is an "innate and universal core folk epistemology" across human cultures (Machery et al. 2015, p. 8). In virtue of their primate nature, humans worldwide share this core knowledge concept.

Of course, it does not follow that all humans have the exact same knowledge concept. Consistent with everything I have said, there could still be important cultural or individual variation in how the core knowledge concept is elaborated, interpreted, or applied (compare Spicer 2010, p. 523 ff; Machery et al., pp. 8-9, 11). Indeed, by analogy with moral judgments, arguably we should expect cultural and individual differences for knowledge judgments. Our moral concepts and sentiments originate from more primitive instincts and mechanisms shared with primates and mammals more generally (Haidt 2007; de Waal 2006; Barnes, Hill, Langer, Martinez \& Santos 2008; Lakshminarayanan \& Santos 2008). And despite our having a suite of species-typical ethical concepts and susceptibilities (e.g. sensitivity to others' welfare, concern for reputation, punitive instincts), we nevertheless exhibit significant cultural and individual variation in moral judgments (for a review, see Young \& Saxe 2011). The same is probably true for knowledge judgments.

It might be asked whether my discussion assumes that we have a reasonably clear and wellmotivated theory of concept identity enabling us to decide when two different groups share a concept. In response, a general theory of concept identity is not required to judge the particular case at hand. We know from modern biology that primates share many genetic, anatomical, social, behavioral, and psychological traits because of their common evolutionary heritage (Mitani, Call, Kappeler, Palombit \& Silk 2012; Stanford, Allen, Antón \& Lovell 2009). The human so- 
cial-cognitive system is based upon a primate social-cognitive system tens-of-millions of years in the making. Thus we should expect many deep and important similarities. Non-human primates have a concept of truth detection, discovery, and retention whose key functions appear to include behavioral predictions and decision-making; primatologists consider this to be a knowledge concept. Humans have a concept with similar criteria and functions; cognitive scientists consider this to be a knowledge concept, and ordinary people use "know" to express it. In light of all this, it is reasonable to conclude that a knowledge concept is part of an ancient primate social-cognitive system. (Those who do not want to call it a "knowledge" concept can call it a "proto-knowledge" concept. Either way, it is still an important epistemological category in primate social cognition.)

In sum, those interested in the human knowledge concept should attend closely to evidence from comparative psychology and especially primate social cognition. Knowledge is a core category of primate social cognition, which implies that humans possess a species-typical knowledge concept whose essence will not be fully understood by studying humans alone.

Acknowledgments - For feedback I thank Wesley Buckwalter, A.Y. Daring, Ashley Keefner, Michael Hannon, Edouard Machery, Stephen Stich, David Rose, and Angelo Turri. This research was supported by the Social Sciences and Humanities Research Council of Canada, the Ontario Ministry of Economic Development and Innovation, and the Canada Research Chairs program.

\section{References}

Alexander, J. (2012). Experimental Philosophy. Cambridge: Polity. 
Aristotle. (350 BCE/1941). Nichomachean ethics. (R. McKeon, Ed., W. D. Ross, Trans.).

Austin, J. L. (1956). A plea for excuses. Proceedings of the Aristotelian Society, 57, 1-30.

Austin, J. L. (1966). Three ways of spilling ink. Philosophical Review, 75(4), 427-440.

Barnes, J. L., Hill, T., Langer, M., Martinez, M., \& Santos, L. R. (2008). Helping behaviour and regard for others in capuchin monkeys (Cebus apella). Biology Letters, 4(6), 638-640. http://doi.org/10.1126/science.1121448

Bray, J., Krupenye, C., \& Hare, B. (2014). Ring-tailed lemurs (Lemur catta) exploit information about what others can see but not what they can hear. Animal Cognition, 17, 735-744.

Buckwalter, W., \& Stich, S. (2014). Gender and philosophical intuition. In J. Knobe \& S. Nichols (Eds.), Experimental philosophy (2nd ed.). Oxford: Oxford University press.

Buckwalter, W., \& Turri, J. (in press). In the thick of moral motivation. Review of Philosophy and Psychology.

Buckwalter, W., \& Turri, J. (2016). Modest scientism in philosophy. In J. R. Ridder, R. Peels, \& R. van Woudenberg (Eds.), Scientism: prospects and problems. Oxford University Press.

Buckwalter, W., Rose, D., \& Turri, J. (2013). Belief through thick and thin. Nous, 1-28. http:// doi.org/10.1111/nous. 12048

Call, J., \& Tomasello, M. (2008). Does the chimpanzee have a theory of mind? 30 years later. Trends in Cognitive Sciences, 12(5), 187-192.

Colaco, D., Buckwalter, W., Stich, S., \& Machery, E. (2014). Epistemic intuitions in fake-barn thought experiments. Episteme, 11(02), 199-212. http://doi.org/10.1017/epi.2014.7

Craig, E. (1990). Knowledge and the state of nature: an essay in conceptual synthesis. Oxford: 
Oxford University Press.

de Waal, F. (2006). Primates and philosophers: how morality evolved. Princeton: Princeton University press.

Ducasse, C. J. (1941). Philosophy as a science: its matter and its method. New York: Oskar Piest.

Flombaum, J. I., \& Santos, L. R. (2005). Rhesus Monkeys Attribute Perceptions to Others. Current Biology, 15(5), 447-452. http://doi.org/10.1016/j.cub.2004.12.076

Fodor, J. A. (1964). On knowing what we would say. The Philosophical Review, 73(2), 198-212.

Goddard, C. (2001). Lexico-semantic universals: a critical overview. Linguistic Typology, 5(1), 1-65.

Haidt, J. (2007). The new synthesis in moral psychology. Science, 316(5827), 998-1002. http:// doi.org/10.1126/science.1137651

Hannon, M. (2015). The universal core of knowledge. Synthese, 1-18. http://doi.org/10.1007/ s11229-014-0587-y

Hare, B., Call, J., \& Tomasello, M. (2001). Do chimpanzees know what conspecifics know? Animal Behaviour, 61(1), 139-151. http://doi.org/10.1006/anbe.2000.1518

Hare, B., Call, J., Agnetta, B., \& Tomasello, M. (2000). Chimpanzees know what conspecifics do and do not see. Animal Behaviour, 59(4), 771-785. http://doi.org/10.1006/anbe. $\underline{1999.1377}$

Hume, D. (1993). An enquiry concerning human understanding. (E. Steinberg, Ed.) (2nd ed.). Indianapolis: Hackett.

Jackson, F. (1998). From metaphysics to ethics. Oxford: Oxford University Press. 
James, W. (1889). The psychology of belief. Mind, 14(55), 321-352.

Kaminski, J., Call, J., \& Tomasello, M. (2008). Chimpanzees know what others know, but not what they believe. Cognition, 109, 224-234.

Kim, M., \& Yuan, Y. (2015). No Cross-Cultural Differences in Gettier Car Case Intuition. Episteme, 12(03), 355-361. http://doi.org/10.1017/epi.2015.17

Knobe, J., \& Burra, A. (2006). The folk concepts of intention and intentional action: a cross-cultural study. Journal of Cognition and Culture, 6(1-2), 113-132.

Knobe, J., Buckwalter, W., Nichols, S., Robbins, P., Sarkissian, H., \& Sommers, T. (2012). Experimental Philosophy. Annu Rev Psychol, 63(1), 81-99. http://doi.org/10.1146/annurevpsych-120710-100350

Lakshminarayanan, V. R., \& Santos, L. R. (2008). Capuchin monkeys are sensitive to others' welfare. Current Biology.

Locke, J. (1690/1975). An essay concerning human understanding. (P. H. Nidditch, Ed.). Oxford: Clarendon Press.

Machery, E. (2004). Semantics, cross-cultural style. Cognition, 92(3), B1-B12. http://doi.org/ 10.1016/j.cognition.2003.10.003

Machery, E., Stich, S., Rose, D., Chatterjee, A., Karasawa, K., Struchiner, N., et al. (2015). Gettier across cultures. Nous.

Marticorena, D. C. W., Ruiz, A. M., Mukerji, C., Goddu, A., \& Santos, L. R. (2011). Monkeys represent others' knowledge but not their beliefs. Developmental Science, 14(6), 14061416. http://doi.org/10.1111/j.1467-7687.2011.01085.x 
Melis, A. P., Call, J., \& Tomasello, M. (2006). Chimpanzees conceal visual and auditory information from others. Journal of Comparative Psychology, 120(2), 154. http://doi.org/ $\underline{10.1037 / 0735-7036.120 .2 .154}$

Mitani, J. C., Call, J., Kappeler, P. M., Palombit, R. A., \& Silk, J. B. (Eds.). (2012). The evolution of primate societies. Chicago: University of Chicago Press.

Murphy, T. (2014). Experimental philosophy: 1935-1965. In T. Lombrozo, J. Knobe, \& S. Nichols (Eds.), Oxford studies in experimental philosophy, volume 1 (pp. 325-367). Oxford University press.

Murray, D., Sytsma, J., \& Livengood, J. (2012). God knows (but does God believe?). Philosophical Studies, 166(1), 83-107. http://doi.org/10.1007/s11098-012-0022-5

Myers-Schulz, B., \& Schwitzgebel, E. (2013). Knowing that P without believing that P. Nous, 47(2), 371-384.

Naess, A. (1938). Common-sense and truth. Theoria, 4(1), 39-58.

Nagel, J., San Juan, V., \& Mar, R. A. (2013). Lay denial of knowledge for justified true beliefs. Cognition, 1-10. http://doi.org/10.1016/j.cognition.2013.02.008

Nichols, S. (2004). Folk concepts and intuitions: from philosophy to cognitive science. Trends in Cognitive Sciences, 8(11), 514-518. http://doi.org/10.1016/j.tics.2004.09.001

Rose, D., Buckwalter, W., \& Turri, J. (2014). When words speak louder than actions: delusion, belief and the power of assertion. Australasian Journal of Philosophy. http://doi.org/ $10.1080 / 00048402.2014 .909859$

Sandel, A. A., MacLean, E. L., \& Hare, B. (2011). Animal Behaviour. Animal Behaviour, 81(5), 
925-931. http://doi.org/10.1016/j.anbehav.2011.01.020

Santos, L. R., Nissen, A. G., \& Ferrugia, J. A. (2006). Rhesus monkeys, Macaca mulatta, know what others can and cannot hear. Animal Behaviour, 71(5), 1175-1181. http://doi.org/ 10.1016/j.anbehav.2005.10.007

Schmelz, M., Call, J., \& Tomasello, M. (2011). Chimpanzees know that others make inferences. Proceedings of the National Academy of Sciences, 108(7), 3077-3079. http://doi.org/ 10.1073/pnas. 1000469108

Seyedsayamdost, H. (2014). On normativity and epistemic intuitions: failure of replication. Episteme, 12(01), 95-116. http://doi.org/10.1017/epi.2014.27

Spicer, F. (2010). Cultural Variations in Folk Epistemic Intuitions. Review of Philosophy and Psychology, 1(4), 515-529. http://doi.org/10.1007/s13164-010-0023-2

Stanford, C., Allen, J. S., Antón, S. C., \& Lovell, N. C. (2009). Biological Anthropology: the natural history of humankind. Toronto: Pearson Education Canada.

Stich, S. (2001). Plato's method meets cognitive science. FRee Inquiry, 21(2), 36-38.

Sytsma, J., \& Livengood, J. (2015). The theory and practice of experimental philosophy. Broadview Press.

Turri, J. (2012). Review of: Achieving Knowledge: A Virtue-Theoretic Account of Epistemic Normativity, by John Greco. Mind, 121(481), 183-187. http://doi.org/10.1093/mind/ fzs032

Turri, J. (2013). A conspicuous art: putting Gettier to the test. Philosophers' Imprint, 13(10), 116. 
Turri, J. (2015a). Unreliable knowledge. Philosophy and Phenomenological Research, 90(3), 529-545. http://doi.org/10.1111/phpr.12064

Turri, J. (2015b). Epistemic situationism and cognitive ability. In M. Alfano \& A. Fairweather (Eds.), Epistemic situationism. Oxford: Oxford University Press.

Turri, J. (2015c). From virtue epistemology to abilism: theoretical and empirical developments. In C. B. Miller, M. R. Furr, A. Knobel, \& W. Fleeson (Eds.), Character: new directions from philosophy, psychology, and theology. Oxford University Press.

Turri, J. (2015d). An open and shut case: epistemic closure in the manifest image. Philosophers' Imprint, 15(2), 1-18.

Turri, J. (2015e). Skeptical appeal: the source-content bias. Cognitive Science, 39(2), 307-324. http://doi.org/10.1111/cogs. 12153

Turri, J. (2016a). How to do better: toward normalizing experimentation in epistemology. In J. Nado (Ed.), Advances in experimental philosophy and philosophical methodology. Bloomsbury Academic.

Turri, J. (2016b). A new paradigm for epistemology: from reliabilism to abilism. Ergo, 3(8), $189-231$

Turri, J. (2016c). Knowledge and the norm of assertion: an essay in philosophical science. Open Book Publishers.

Turri, J. (in press a). Knowledge attributions and behavioral predictions in social cognition. Cognitive Science.

Turri, J. (in press b). Experimental, cross-cultural, and classical Indian epistemology. Journal of 
Indian Council of Philosophical Research.

Turri, J., \& Buckwalter, W. (2017). Descartes's schism, Locke's reunion: completing the pragmatic turn in epistemology. American Philosophical Quarterly, 54(1)..

Turri, J., Buckwalter, W., \& Rose, D. (2016). Actionability judgments cause knowledge judgments: evidence from two experiments. Thought.

Turri, J., Friedman, O., \& Keefner, A. (2017). Knowledge central: a central role for knowledge attributions in social evaluations. Quarterly Journal of Experimental Psychology, 70(3), 504-515. http://doi.org/10.1080/17470218.2015.1136339.

Weinberg, J. M., Nichols, S., \& Stich, S. (2001). Normativity and epistemic intuitions. Philosophical Topics, 29(1\&2), 429-460.

Young, L., \& Saxe, R. (2011). Moral Universals and Individual Differences. Emotion Review, 3(3), 323-324. http://doi.org/10.1177/1754073911402383 